\title{
A EXECUÇÃO PROVISÓRIA DA PENA PRIVATIVA DE LIBERDADE E SUA COMPATIBILIZAÇÃO COM O PRINCÍPIO DA PRESUNÇÃO DA INOCÊNCIA
}

\author{
Gabriel Pantaroto Lima, Eduardo Buzetti Eustachio Bezerro \\ Universidade do Oeste Paulista - UNOESTE, curso de Direito, Presidente Prudente, SP. E-mail: \\ gabrielpantarotolima@gmail.com
}

\section{RESUMO}

A presente pesquisa refere-se ao início da execução da pena, após confirmação condenatória em segundo grau, em harmonia com o principio da presunção da inocência, sendo esse um tema que divide opiniões no cenário jurídico brasileiro, haja vista a recente mudança de posicionamento do Supremo Tribunal Federal, após o julgamento do Habeas Corpus no 126.292. Assim sendo, a presente pesquisa objetiva analisar o entendimento da Suprema Corte, bem como sua constitucionalidade, destacando os principais argumentos encontrados.

Palavras-chave: Execução provisória. Pena privativa de liberdade. Constitucionalidade. Princípio da presunção de inocência.

\section{THE PROVISIONAL IMPLEMENTATION OF THE FREEDOM OF PRIVATE PEN AND ITS COMPATIBILITY WITH THE PRINCIPLE OF PRESUMPTION OF INNOCENCE}

\begin{abstract}
This research refers to the beginning of the sentence after convicting confirmation in the second degree, in accordance with the principle of presumption of innocence, this being an issue that divides opinion in the Brazilian legal scenario, given the recent change of position the Supreme Court after the judgment of Habeas Corpus no 126,292. Thus, this research aims to analyze the understanding of the Supreme Court and its constitutionality, highlighting key arguments found. Keywords: Provisional enforcement. Deprivation of liberty. Constitutionality. Principle of presumption of innocence.
\end{abstract}




\section{INTRODUÇÃO}

O princípio da presunção da inocência, previsto na Constituição Federal em seu artigo 5으, inciso LVII, preceitua que "ninguém será considerado culpado até o trânsito em julgado de sentença penal condenatória". Tal direito garante ao acusado todos os meios de defesa cabíveis, garantindo que não será declarado culpado até que a sentença transite em julgado. O Supremo Tribunal Federal ao julgar o Habeas Corpus no 126.292, fez surgir uma nova interpretação quanto ao momento terminativo da presunção da inocência, dando imediato inicio à execução após condenação em segunda instancia.

A nova interpretação da Suprema Corte fez com que surgisse uma discussão meio acadêmico-jurídico brasileiro. Alguns juristas favoráveis à decisão argumentam ser correta, por amparar a sociedade buscando uma efetividade da função jurisdicional. Outros argumentam ser à decisão incorreta e inconstitucional por violar direitos e garantias fundamentais do indivíduo, não sendo essa a melhor forma de buscar a efetividade da função jurisdicional.

Dessa forma, o presente artigo tem por objetivo mostrar os posicionamentos no aspecto constitucional e doutrinário referente ao tema, bem como expor conceitos, fundamentações e argumentos importantes para máxima compreensão dos leitores.

\section{METODOLOGIA}

A metodologia utilizada na presente pesquisa foi desenvolvida a partir de levantamento bibliográfico em livros, artigos eletrônicos, julgamentos de Tribunais entre outros, leitura e fichamento. Os dados coletados serão interpretados, confrontados e discutidos, utilizando-se do método dialético, cujo foco é a contraposição e contradição de ideias através do diálogo, utilizando-se de argumentos e contra-argumentos, sendo desenvolvendo no decorrer do trabalho opinião sobre o tema.

\section{PRINCIPIO DA PRESUNÇÃO DA INOCENCIA}

O princípio da presunção da inocência, também conhecido como princípio do estado de inocência ou da não culpabilidade, é um princípio previsto expressamente na Constituição da República, em seu artigo 5ㅇ, inciso LVII, que diz que "ninguém será considerado culpado até o trânsito em julgado da sentença condenatória".

Trata-se, pois, de um princípio constitucional explícito, previsto, também na Declaração Universal dos Direitos Humanos da ONU, no Pacto Internacional sobre Direitos Civis e Políticos e no Pacto San José da Costa Rica. Tratados esses, que o Brasil é signatário e, segundo o artigo 5o, $\S$ 30 , da Constituição Federal, equivalem às emendas constitucionais.

Renato Brasileiro Lima (2012, p.11) expõe que:

Consiste no direito de não ser declarado culpado senão mediante sentença transitada em julgado, ao término do devido processo legal, em que o acusado tenha se utilizado de todos os meios de prova pertinentes para sua defesa (ampla defesa) e para a destruição da credibilidade das provas apresentadas pela acusação (contraditório) (LIMA, 2012, p. 11).

A expressão "presunção de inocência" não pode ser interpretada ao pé da letra, literalmente, do contrário os inquéritos e os processos não seriam toleráveis, posto não ser possível inquérito ou processo em relação a uma pessoa inocente.

\section{EXECUÇÃO DA PENA APÓS CONFIRMAÇÃO CONDETÓRIA EM SEGUNDO GRAU: ANÁLISE DO ENTENDIMENTO DO SUPREMO TRIBUNAL FEDERAL}

A possibilidade da execução provisória da pena privativa de liberdade após condenação do réu em segunda instancia, era orientação que prevalecia na jurisprudência do Supremo Tribunal Federal, mesmo na vigência da Constituição Federal de 1988. 
Nesse cenário jurisprudencial, o Supremo Tribunal Federal no julgamento do Habeas Corpus no 68.726, realizado em 28 de junho de 1991, assentou que a presunção de inocência não impede a prisão decorrente de acórdão que confirmou a sentença penal condenatória.

Em diversas oportunidades, as turmas do Supremo Tribunal Federal afirmaram e reafirmaram que o princípio da presunção da inocência não inibia a execução provisória da pena imposta, ainda que pendente recurso especial ou extraordinário.

A alteração dessa tradicional jurisprudência veio a ocorrer no julgamento do Habeas Corpus no 84.078, realizado em 05 de fevereiro de 2009, oportunidade em que, por sete votos a quatro, assentou-se que o princípio da presunção de inocência se mostra incompatível com a execução da sentença antes do trânsito em julgado da condenação.

Então, que em 17 de fevereiro de 2016, ao julgar o HC no 126.292 por maioria de votos, o Supremo Tribunal Federal mudou seu entendimento, no que se refere à possibilidade de execução provisória da pena. A partir daí, entendendo que o início da execução da pena, após a confirmação da sentença condenatória em segundo grau, não ofende o princípio constitucional da presunção da inocência.

O argumento utilizado pelo Supremo Tribunal Federal foi que "em país nenhum do mundo, depois de observado o duplo grau de jurisdição, a execução de uma condenação fica suspensa, aguardando referendo da Corte Suprema". Contudo, alguns juristas criticam, argumentando que "nenhum país traz a concepção de presunção de inocência como a prevista na Constituição brasileira".

Antes de prolatada a sentença penal há de se manter a presunção de inocência do acusado. A eventual condenação representa um juízo de culpabilidade, que deve ser extraído das provas produzidas no regime do contraditório no curso da ação penal.

Para o juiz de primeiro grau, fica superada a presunção de inocência por um juízo de culpa, embora não definitivo, já que o acusado tem o direito, se houver recurso, à revisão do Tribunal de hierarquia superior.

Em segundo grau fica exaurido o exame sobre os fatos e provas da causa, com a fixação da responsabilidade penal do acusado, concretizando o princípio constitucional do duplo grau de jurisdição. $\mathrm{O}$ acusado fica assegurado ao direito de liberdade antes do acórdão desse juízo de segundo grau, respeitadas as prisões provisórias.

É, portanto, na revisão em segundo grau que se exaure a possibilidade de exame de fatos e provas e, sob esse aspecto, a própria da fixação da responsabilidade do acusado.

Tendo em segundo grau, um juízo de incriminação do acusado, fundado em fatos e provas, insuscetível de reexame pela instância extraordinária se exaure a observação ao princípio da presunção da inocência.

Esgotadas as instâncias ordinárias com a condenação à pena privativa de liberdade, tem-se uma declaração, com considerável força de que o réu é culpado e a sua prisão necessária.

A execução da pena na pendência de recursos de natureza extraordinária não compromete o princípio da presunção da inocência, visto que o causado foi tratado como inocente todo o processo ordinário criminal, observado os direitos e as garantias a ele inerentes, bem como respeitadas as regras probatórias. É possível autorizar, a partir daí, ainda que cabíveis ou pendentes de julgamento recursos extraordinários, a produção dos efeitos próprios da responsabilização criminal reconhecida pelas instâncias ordinárias.

\section{ASPECTOS CONSTITUCIONAIS E DOUTRINARIOS}

Junto ao novo entendimento do Supremo Tribunal Federal surgiu uma divisão na doutrina, sem posicionamento majoritário.

Alguns doutrinadores apoiam à decisão da Suprema Corte, argumentando que, sendo o acusado em segunda instancia preso, evitará o ajuizamento de recursos de caráter protelatório, 
que apenas visam retardar o processo, dando a sociedade uma efetiva prestação jurisdicional do Estado, contendo o clamor público com sensação de justiça.

Outros doutrinadores não concordam com novo entendimento da Suprema Corte, argumentam ser à decisão inconstitucional, por violar direitos e garantias fundamentais do indivíduo, sendo um retrocesso à perda de um direito adquirido ao longo da história. Como medida alternativa, os mesmos aconselham a redução de recursos ou o ampliamento de seus requisitos, assim, dificultando sua interposição, ao invés de afrontar à Constituição.

Como mencionado anteriormente, o Brasil é signatário à Declaração Universal dos Direito Humanos das Nações Unidas, de 1948, cujo artigo 11 estabelece:

Toda pessoa acusada de um ato delituoso tem o direito de ser presumida inocente até que a sua culpabilidade tenha sido provada de acordo com a lei, em julgamento público no qual the tenham sido asseguradas todas as garantias necessárias à sua defesa.

A decisão proferida no HC no 126.292, não está de acordo com as diretrizes da Constituição Federal e, nos países onde o regime político-jurídico adotado é Estado Democrático de Direito, as principais regras da coexistência são as previstas na sua constituição.

Também em sentido contrário, o artigo 283 do Código de Processo Penal expõe:

Ninguém poderá ser preso senão em flagrante delito ou por ordem escrita e fundamentada da autoridade judiciária competente, em decorrência de sentença condenatória transitada em julgado ou, no curso da investigação ou do processo, em virtude de prisão temporária ou prisão preventiva.

O artigo 283 do Código de Processo Penal, no entender de alguns juristas, deveria ser considerado inconstitucional, o que não ocorreu, pois, caso uma norma infraconstitucional reproduza, repita, copie o teor de uma norma constitucional, terá sua constitucionalidade espelhada, por refletir o que esta no artigo 5으, inciso LVII da Constituição Federal.

\section{RECURSOS}

Os recursos pressupõem inconformismo, insatisfação com as decisões judiciais, e que buscam outro pronunciamento do Poder Judiciário a respeito das questões a ele submetidas.

No entender de Marcus Vinicius Rios Gonçalves (2016, p. 846):

Recursos são os remédios processuais de que se podem valer as partes, 0 Ministério Público e eventuais terceiros prejudicados para submeter uma decisão judicial a nova apreciação, em regra por um órgão diferente daquele que a proferiu, e que têm por finalidade modificar, invalidar, esclarecer ou complementar a decisão. (GONÇALVES, 2016, p. 846).

Enquanto há recurso pendente, a decisão impugnada não se terá tornado definitiva. As decisões judiciais não se tornam definitivas, enquanto houver a possibilidade de interposição de recurso, ou enquanto os recursos pendentes não tiverem sido examinados, isso não significa que a decisão impugnada não pode desde logo produzir efeitos. Há recursos que são dotados de efeito suspensivo, e outros que não são. Somente os que possuem este efeito, terão suspensão da eficácia da decisão.

Os recursos cabíveis contra decisões de segunda instancia, são os recursos extraordinários lato sensu, sendo eles o recurso especial e recurso extraordinário stricto sensu.

É, portanto, na segunda instancia que se exaure a possibilidade de exame de fatos e provas e, sob esse aspecto, a própria fixação da responsabilidade criminal do acusado. 
O recurso especial e o extraordinário stricto sensu são dotados de efeito devolutivo, cujo objetivo é devolver toda matéria para reexame em instância superior, para que a sentença seja anulada, reformada, ou, também, mantida. Porém os efeitos dessa sentença continuam vigentes. Os mesmos não são dotados de efeito suspensivo, cujo objetivo é tornar a sentença inexecutável, até o julgamento do recurso, ficando suspensos seus efeitos.

Desta forma, em simples síntese, tanto o efeito devolutivo quanto o suspensivo devolvem a matéria para reexame, porém, no primeiro, permanecem vigentes os efeitos da sentença prolatada; enquanto no segundo os efeitos da sentença ficaram suspensos até que seja feito novo julgamento.

Atribuir apenas efeito devolutivo aos recursos especial e extraordinário é, sob esse aspecto, mecanismo legítimo de harmonizar o princípio da presunção de inocência com o da efetividade da função jurisdicional.

É importante salientar que o réu poderá tentar evitar a execução provisória da pena no ato da interposição do recurso especial ou do recurso extraordinário, pedindo cautelarmente que seja conferido efeito suspensivo à decisão recorrida, nos termos do artigo 1.029 , § 50, do novo Código de Processo Civil. Cumpre referir que se o réu condenado em segunda instancia, opuser embargos de declaração, o início da execução provisória da pena ficará suspenso até o seu julgamento, pois essa modalidade de recurso possui efeito suspensivo, impedindo que a decisão embargada produza efeitos.

\section{CONCLUSÃO}

É justificável, a possibilidade de o julgador determinar o imediato início do cumprimento da pena, com restrição da liberdade do acusado, depois de firmada a responsabilidade criminal pelas instâncias ordinárias.

Buscando a pacificação social, a Suprema Corte acertou ao julgar o Habeas Corpus no 126.296. Com isso, foi restaurado o equilíbrio entre o direito à liberdade e a eficiência jurisdicional, sendo claramente, esta decisão um reflexo da criminalidade e impunidade presente no Brasil, onde pessoas com alto poder financeiro parecem não ser alcançadas pela lei. Entretanto, devemos reconhecer que, ao agir assim a Suprema Corte afrontou o princípio da presunção da inocência, atendendo aos anseios sociais, dado o momento histórico de combate a corrupção que o país atravessa.

Por essas razões a execução da pena após confirmação em segundo grau, ainda que sujeito recurso especial ou extraordinário, não compromete o princípio constitucional da presunção de inocência.

\section{REFERÊNCIAS}

BRASIL, Supremo Tribunal Federal. Habeas Corpus no 84.078 Ministro EROS GRAU. Disponível em: <http://www.stf.jus.br/arquivo/cms/noticiaNoticiaStf/anexo/ementa84078.pdf>. Acesso em: 27 abr. 2016.

BRASIL, Supremo Tribunal Federal. Habeas Corpus no 126.292. Ministro TEORI ZAVASCKI. Disponível em:<http://www.migalhas.com.br/arquivos/2016/2/art20160217-10.pdf>. Acesso em $27 \mathrm{abr} .2016$.

BRASIL, Supremo Tribunal Federal. Habeas Corpus no 126.292 Ministro CELSO DE MELLO. Disponível em:<http://www.migalhas.com.br/arquivos/2016/2/art20160223-10.pdf >. Acesso em 14 ago. 2016. 
BRASIL, Supremo Tribunal Federal. Habeas Corpus no 126.292 Ministro MARCO AURÉLIO. Disponível em:< http://www.migalhas.com.br/arquivos/2016/2/art20160225-06.pdf>. Acesso em 14 ago. 2016.

BRASIL, Supremo Tribunal Federal. Habeas Corpus no 126.292 Ministro LUÍS ROBERTO BARROSO. Disponível em: <http://www.migalhas.com.br/arquivos/2016/2/art20160218-01.pdf>. Acesso em 14 ago. 2016.

FREITAS, Fladimir Passos. Supremo Restaura Equilíbrio ao Determinar Execução Provisória da Pena. Disponível em: http://www.portaleducacao.com.br/pedagogia/artigos/48764/referenciasbibliograficas-tiradas-na-internet-como-colocar-no-trabalho. Acesso em 14 de ago. 2016.

GONÇALVES, Marcus Vinicius Rios. Direito Processual Civil Esquematizado. 6. ed. Saraiva. São Paulo, 2016.

LIMA, Renato Brasileiro. Manual de Processo Penal. 1. ed. Niterói. Impetus, 2012. 